\title{
Kepuasan Kerja sebagai Variabel Intervening Pada Pengaruh Work-Life Balance dan Stres Kerja Terhadap Turnover Intention
}

\author{
Muhammad Andi Prayogi ${ }^{1 *}$, Murviana Koto $^{1}$, Muhammad Arif $^{1}$ \\ Fakultas Ekonomi dan Bisnis, Universitas Muhammadiyah Sumatera Utara \\ Jl. Kaptem Mukhtar Basri No. 3 Medan, Sumut, Indonesia \\ *Email: muhammadandi@umsu.ac.id
}

\begin{tabular}{c}
\hline Artikel Info \\
\hline Received: \\
6 Desember 2018 \\
Revised: \\
15 Maret 2019 \\
Accepted: \\
30 Maret 2019 \\
\hline
\end{tabular}

\begin{abstract}
ABSTRAK
Penelitian ini bertujuan untuk membuktikan pengaruh Work-Life Balance dan stres kerja terhadap turnover intention dimediasi kepuasan kerja Account officer Bank Syariah di Kota Medan. Lokasi penelitian ini berada di Kota Medan dengan subyek penelitian adalah Bank Syariah di Kota Medan, Populasi penelitian ini berjumlah 150 Account Officer, dengan teknik pengambilan sampel menggunakan Probability Sampling dengan teknik simple random sampling, penentuan sampel menggunakan rumus Slovin. Teknik analisa data dalam penelitian ini menggunakan path analysis. Hasil Penelitian secara parsial menunjukkan bahwa Work life balance dan Stres kerja berpengaruh positif dan signifikan terhadap kepuasan kerja, Work life balance dan stress kerja berpengaruh positif dan signifikan terhadap turnover intention, Kepuasan kerja berpengaruh negatif dan signifikan terhadap turnover intention. Work life balance berpengaruh secara langsung terhadap turnover intention tanpa melalui kepuasan kerja, kepuasan kerja bukan variabel intervening, Stres kerja berpengaruh secara langsung terhadap turnover intention tanpa melalui kepuasan kerja, kepuasan kerja bukan variabel intervening.
\end{abstract}

Kata Kunci: Work-life Balance, Kepuasan Kerja,Stress Kerja, Turnover Intention

The Effect of Job Satisfaction Mediation on The Influence of Work-Life Balance and work stress on Turnover Intention

\begin{abstract}
This study aims to prove the effect of Work-Life Balance and work stress on turnover intention mediated by job satisfaction of Bank Syariah Account Officers in Medan. The location of this research is in the city of Medan with the subject of research is the Sharia Bank in the city of Medan, the population of this study amounted to 150 Account Officers, with sampling techniques using Probability Sampling with simple random sampling techniques, determining the sample using the Slovin formula. Data analysis techniques in this study used path analysis. The research results partially showed that Work-life balance and work stress had a positive and significant effect on job satisfaction, Work-life balance and work stress had a positive and significant effect on turnover intention, job satisfaction had a negative and significant effect on turnover intention. Work-life balance directly influences turnover intention without going through job satisfaction, job satisfaction is not an intervening variable, Job stress has a direct effect on turnover intention without going through job satisfaction, job satisfaction is not an intervening variable.
\end{abstract}

Keywords: Work-life balance, job satisfaction, job stress, turnover intention

Cara Sitasi:

Prayogi, M. A., Koto, M., Arif, M., (2019). Kepuasan Kerja sebagai Variabel Intervening Pada Pengaruh Work-Life Balance dan Stres Kerja Terhadap Turnover Intention. Jurnal Ilmiah Manajemen dan Bisnis, 20(1), 39-51. https://doi.org/10.30596/jimb.v20i1.2987 


\section{PENDAHULUAN}

Sumber daya manusia (SDM) adalah asset yang berharga dalam organisasi baik itu organisasi formal dan bersifat non formal baik yang merupakan organisasi profit atau organisasi profit, karena dengan adanya SDM dalam organisasi tersebut dapat berjalan dengan baik, sumber daya manusia yang ada diperbankan sangat perlu untuk dikembangkan apalagi SDM tersebut memiliki kemampuan yang dapat membantu untuk meningkatkan nilai-nilai dan profit perbankan, maka sudah seharunya bagi dunia perbankan untuk dapat memberikan timbal balik yang sesuai bagi SDM yang memiliki kinerja yang baik agar dapat memberikan kepuasan tersendiri bagi SDM yang ada serta menjaga SDM tersebut agar tidak meningglkan organisasi (Prawitasari, 2016), (Abdurrahim \& Anisah, 2015).

Pasal 19 No Undang-undang Nomor 21 Tahun2008 tentang Perbankan Syariah, kegiatan usaha Bank Umum Syariah adalah meliputi menghimpun dana dalam bentuk simpanan berupa Giro, tabungan atau bentuk lainnya yang dipersamakan dengan itu berdasarkan Akad Wadia'ah dan Mudarhabah atau akad lain yang tidak bertentangan dengan prisnsip syariah. Selanjutnya menyalurkan pembiayaan dana dalam bentuk investasi berdasarkan akad mudharabah, musyarakah, atau akad lain yant tidak bertentangan dengan prinsip syariah. Account officer dalam melaksanakan tugas tugasnya di perbankan syariah harus melakukan berkasberkas survey kepada calon nasabah dan mencari nasabah-nasabah baru, aktivitas tersebut ditangani oleh Account officer sebagai mana yang dikatakan (Syakir, 2014). Perkembangan perbankan syariah di tanah air sangat pesat, khususnya di sektor pembiayaan disebabkan semakin gencarnya informasi dan edukasi yang diterima oleh masyarakat, disnilah seorang Account officer banyak dilibatkan. Account officer memiliki tugas yang dimulai dari memberikan kredit hingga pemberian pemberikan kredit hingga pemberian kredit itu berakhir (Dini \& Sari, 2013).

Jika Account officer memiliki niat untuk keluar (turnover intentions) yang tinggi akan berdampak negatif bagi perusahaan, sehingga suasana kerja akan tercipta ketidakstabilan terhadap kondisi karyawan dan perusahaan tidak dapat meningkatkan SDMnya, hal ini dapat menjadikan perusahaan tidak efektif dan efisien, karena perusahaan akan kehilangan karyawan yang memiliki kemampuan dan pengalaman, dan perusahaan perlu merekrut karyawan baru dan melatih kembali, dan mengeluarkan biaya yang cukup besar, dengan kata lain Kinerja SDM perbankan ditentukan oleh koondisi dan perilaku perilaku karyawan yang dimiliki perusahaan tersebut (Hidayati \& Trisnawati, 2016 ; Nasution, 2009)).

Permalasahan yang ditemui pada perbankan syariah memperlihatkan bahwa Account officer yang suka membawa masalah pribadi kedalam lingkungan pekerjaan, dimana perusahaan tidak memiliki wewenang untuk mencampuri urusan pribadi account officer, tetapi apabila urusan pribadi tidak diselesaikan maka akan mengganggu pekerjaan. Pekerjaan rumah sering di bawa ke kantor sehnigga ini juga menjadi permasalahan yang bisa mengakibatkan pertengkaran kepada keluarga maupun karena keluarga menjadi terabaikan demi pekerjaan kantor. Aktivitas sebagai seorang Account officer sangat membuat jenuh karena setiap harus berhadapan dengan calon-calon nasabah yang harus dikejar sesuai target yang telah ditetapkan oleh perusahaan dalam sehingga hal ini bisa mengakibatkan turunnya kinerja dan akan berdampak kepada keinginan untuk keluar dari perusahaan dan mencari pekerjaan lain, sebagaimana yang dijelaskan (Nafiudin, 2015) Karyang yang tidak mampu menjaga hubungan harmonis di perusahaan dimana karyawan tidak bisa memilah antara pekerjaan dan kehidupan 
keluarga, maka karyawan akan memilik untuk mencari pekerjaan lain atau memilih behenti dari perusahaan karena karyawan itu menganngap Work life balance penting dalam menjalani pekerjaan. Sedangkan jika karyawan itu dapat menjaga keharmonisan perkjaan dan kehidupan pribadi, tentunya akan merasakan kepuasan kerja. Turnover intention memilihi hubungan yang kuat dengan Job Satisfaction, disaat karyawan merasakan kepuasan kerja, maka karyawan akan cenderung bertahan untuk tidak meninggalkan pekerjaan. Pada kenyataaan di lapangan Account officer menyebutkan bahwa tidak mudah mengatur keseimbangan antara kehidupan pekerjaan dan kenyataan yang mereka hadapi. Pengaturan tidaklah mudah saat Account officer memiliki masalah diluar pekerjaannya, dalam hal ini masalah dengan keluarga, masalah tersebut akan menyita perhatian account officer, masalah yang membebani pikiran Account officer akan terbawa dalam pekerjaan, fleksibilitas jam kerja akan sangat sangat bermanfaat untuk mencapai work-life dapat mengurangi kecenderungan untuk mengundurkan diri dan mengurangi tingkat absen (Bintang \& Astiti, 2016). Sementara Menurut (Nurendra \& Saraswati, 2016) Work-life balance merupakan keadaan yang memiliki keseimbangan dimana ada tuntutan pekerjaan dan kehidupan pribadi seseorang adalah sama. Dalam persepi karyawan keseimbangan pekerjaan merupakan pilihan antara mengatur kewajiban kerja dan kewajiban dalam kehidupan pribadi, atau tanggungjawab pada keluarga. Sedangkan perusahaan memiliki persepsi yang berbeda, work-life balance merupakan suatu kondisi yang menandant untuk bisa menciptakan dan mendukung budaya kerja yang berfokus pada pekerjaan ditempat kerja.

Fakta lain yang dihadapi para Account officer adalah sebagi seorang karyawan yang berstatus sudah memiliki keluarga dan anak, mereka merasakan cukup berat mengatur keseimbangan pada saat menghadapi beban kerja yang cukup berat yang pada setiap bulannya harus dikejar oleh target yang ditetapkan oleh perusahaan sehingga akan terbawa-bawa dalam kehidupan keluarga sesuai dengan apa yang diungkapkan. Menurut Nafiudin (2015), jika seseorang tidak dapat mengatur Work life balance antara pekerjaan dan kehidupan pribadi maka dapat diindikasikan seseorang tersebut akan memilih berhenti untuk bekerja, jika Work life balance seorang karyawan tidak tercapai maka dapat menimbulkan stres kerja.

Umumnya jam kerja karyawan adalah 8 jam dalam sehari. Namun deadline tugas yang diberikan oleh Perushaan Bank menyebabkan Account officer bekerja lebih dari 8 jam sehari, sehingga Account officer dituntut untuk melaksanakan tanggungjawabnya sehingg perusahaan mengabaikan Work-life balance seperti target yang harus dikejar, mengerjakan tugas-tugas yang harus segera diselsaikan sehingga para Account officer harus kerja lembur (over time), disamping itu juga kenyataan yang dialami Account officer adalah tidak sesuainya kompensasi yang diberikan, masalah-masalah yang terjadi didalam keluarga. Ketidakpuasan dengan hasil target yang diperoleh, Tidak nyaman dalam melakukan aktivitas kerja, Mitra kerja/relasi atau rekan kerja tidak memberikan dukungan terhadap pekerjaan, Jenuh dan bosan dengan pekerjaan sehari-hari yang dihadapi Tekanan yang datang dari keluarga, tekanan dari atasan yang terlalu berat yang tidak sesuai dengan kemampuan tetapi harus bisa dicapai, seperti yang dikatakan Maslichah \& Hidayat, (2017), (Asepta \& Maruno, 2007).

Turnover intention merupakan bentuk merupakan keadaan kondisi dari seseporang yang memiliki niat untuk meninggalkan perusahaan, dan mencari pekerjaan lain yang lebih baik Harnoto, (2002), sedangkan 


\section{Published April 2019 \\ JURNAL ILMIAH MANAJEMEN DAN BISNIS \\ ISSN 1693-7619 (print) | ISSN 2580-4170 (online), http://jurnal.umsu.ac.id/index.php/mbisnis}

Nafiudin \& Umdiana, (2017) menerangkan bahwa Turnover intention adalah niat seseorang untuk meninggalkan pekerjaan dan mencari pekerjaan lain yang lebih baik pada masa yang akan datang. Faktor-faktor yang Mempengaruhi Turnover. Seperti yang dijelaskan Nisa, et al, (2012) dapat dibedakan menjadi dua faktor, yaitu "1) Faktor organisasional antara lain: Pergantian karyawan lebih banyak terjadi diantara : (1) tenaga kerja kasar daripada tenaga kerja halus, tingkat-tingkat keterampilan yang lebih endah di kalangan tenaga kasar, kategorikategori yang bukan manajerial. 2) Besar kecilnya Organisasi. Secara konseptual, besar-kecilnya organisasi, 3) Besar Kecilnya Unit Kerja. 4) Penggajian. Sedagkan faktor Individual yaitu usia, masa kerja. jenis Kelamin. pendidikan, data Biografik, minat, bakat dan kemampuan". Hidayati \& Trisnawati, (2016) menjelaskan Turnover intentions diukur dengan empat tindakan yaitu adanya niat untuk keluar, mencari lowongan pekerjaan, mengevaluasi kemungkinan megemukan pekerjaan lain. dan memiliki keinginan yang kuat untuk berpindah perusahaan.

Hutcheson, (2012) menjelaskan bahwa Work-Life Balance adalah suatu bentuk kepuasan pada individu dalam mencapai keseimbangan kehidupan dalam pekerjaannya. Dari beberapa defenisi tersebut work-life balance yang telah dikemukakan dapat disimpulkan bahwa worklife balance adalah Situasi atau kondisi dimana para karyawan dapat memberikan keseimbangan antara tuntutan pekerjaan dengan kebutuhan pribadi dan keluarganya. Indikator-indikator untuk mengukur keseimbangan kehidupan-kerja menurut McDonald \& Bradley, (2005); Asepta \& Maruno, (2007) yaitu: 1). Keseimbangan waktu, 2). Keseimbangan keterlibatan psikologis dan komitmen dalam bekerja atau di luar pekerjaan. 3) Keseimbangan kepuasan kerja.
Luthans, (2006) mendefenisikan "kepuasan kerja adalah meliputi reaksi atau sikap kognitif, afektif, dan evaluatif dan menyatakan bahwa kepuasan kerja adalah keadaan emosi yang senang atau emosi positif yang berasal dari penilaian pekerjaan atau pengalaman kerja seseorang, sedangkan Kepuasan kerja (job satisfaction) adalah suatu perasaan positif tentang pekerjaan seseorang yang merupakan hasil dari evaluasi karakteristiknya (Robbins \& Judge, 2008). Robbins, (2012) mengemukakan beberapa faktor penting dalam kepuasan kerja yaitu: (1) pekerjaan yang menantang; (2) pemberian gaji yang adil; (3) kondisi kerja yang mendukung; serta (4) rekan kerja yang mendukung. Indikator yang digunakan untuk variabel kepuasan kerja menurut (Manurung \& Ratnawati, 2012) yaitu: work it self (pekerjaan itu sendiri), salary (gaji/upah), promotional opportunitie (kesempatan promosi), supervisor (pengawasan), dan work relations (rekan kerja).

Stres kerja menurut Handoko, (2011) merupakan kondisi yang mempengaruhi emosi, proses berpikir dan kondisi seseorang, sttes yang terlalu besar dapat mengancam kemampuan seseorang untuk menghadapi lingkungan, Kondisi-kondisi yang cenderung menyebabkan stres disebut stressors, Indikator stres kerja adalah: 1) Indikator pada psikologis, meliputi : a) Cepat tersinggung b) Tidak komunikatif c) Banyak melamun d) Lelah mental 2) Indikator pada fisik, meliputi : a) Meningkatnya detak jantung b) Meningkatnya tekanan darah c) Mudah lelah secara fisik d) Pusing e) Sulit tidur 3) Indikator pada prilaku, meliputi : a) Merokok berlebihan b) Menunda pekerjaan c) Perilaku sabotase d) Pola makan tidak teratur (Astianto \& Suprihhadi, 2014).

Mayoritas faktor yang menganggu work-life balance pada kehidupan pekerjaan adalah permasalahan dengan rekan kerja, kehidupan pribadi, kehidupan sosial, karena berbenturan dengan waktu adat dan waktu 


\section{Published April 2019 \\ JURNAL ILMIAH MANAJEMEN DAN BISNIS \\ ISSN 1693-7619 (print) | ISSN 2580-4170 (online), http://jurnal.umsu.ac.id/index.php/mbisnis}

bekerja (Bintang \& Astiti, 2016), hal ini terbukti dengan penelitian-penelitian sebelumya yang telah dilakukan oleh Asepta \& Maruno, (2007), Risna, et al., (2017), yang menyatakan bahwa ada pengaru Work-Life Balance (Keseimbangan Kehidupan Kerja) terhadap kepuasan kerja, ini menunjukkan bahwa worklife balance pada suatu perusahaan sangatlah penting. Penelitian selanjutnya yang dikemukakan oleh Wibowo, et, al, (2015), Dewi, et al, (2014) stres kerja memiliki pengaruh negatif terhadap kepuasan kerja. Hal ini bermakna bahwa stres kerja yang dialami oleh karyawan dapat mempengaruhi apa yang mereka rasakan baik itu menyangkut pekerjaan maupun hasil yang mereka terima. Nazenin \& Palupiningdyah, 2014). Seperti halnya penelitian Hidayati \& Trisnawati, (2016) Saraswati \& Subudi, (2017), Ulil Amri \& Riyanto, (2017) yang mengatakan Stress kerja berpengaruh terhadap turnover intention. Kemudian pengaruh Sudita, (2015) mengatakan bahwa kepuasan kerja berpengaruh negatif signifikan terhadap turnover intention. Penelitian berikutnya bahwa work-life balance berpengaruh terhadap turnover intention yang dimediasi oleh kepuasan kerja, ini dibuktikan dengan penelitian (Oosthuizen, Coetzee, \& Munro, 2016), (Noor, 2011), bahwa kepusan kerja sebagai variabel intervening. Berikutnya adalah penelitian yang dilakukan Pahi, et al, (2016), Dewi \& Wibawa, (2016) yang menyatakan bahwa stres kerja berpengaruh terhadap tunrover intention dimediasi kepuasan yang menyatakan bahwa stres kerja berpengaruh terhadap tunrover intention, bahwa kepuasan kerja sebagai variabel intervening.

Seperti yang telah yang telah dikemukakan di atas, maka identifikasi Worklife balance dan stress kerja terhadap turnover intention dengan melibatkan kepuasan kerja sebagai variabel intervening menjadi masalah yang menarik untuk dilakukan penelitian, agar menjadi temuan- temuan baru didalam bidang sumber daya manusia. Berdasarkan kajian teori dan penelitan terdahulu, maka dapat dijelaskan kerangka konseptual penelitian ini sebagai berikut:

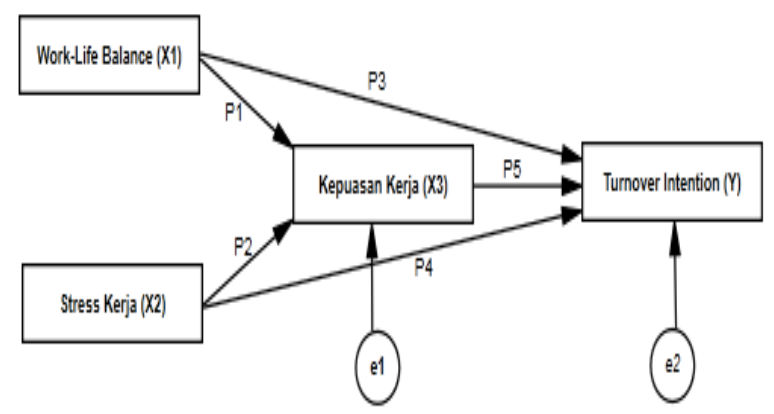

Gambar 1. Kerangka Konseptual

Atas dasar teori dan penelitian terdahulu yang telah dijelaskan, maka hipotesis penelitian sebagai berikut: H1: Ada pengaruh positif dan signifikan Work-Life Balance terhadap kepuasan kerja Account officer Bank Syariah di Kota Medan, H2: Ada pengaruh negatif dan signifikas stres kerja terhadap kepuasan kerja Account officer Bank Syariah di Kota Medan. H3: ada pengaruh positif dan signifikan Work-life Balance terhadap turnover intention Account officer Bank Syariah di Kota Medan, H4: Ada pengaruh positif dan signifikan stres kerja terhadap turnover intention Account officer Bank Syariah di Kota Medan, H5: Ada pengaruh negatif dan signifikan kepuasan kerja terhadap turnover intention Account officer Bank Syariah di Kota Medan, H6: Ada pengaruh tidak langsung antara Work-life Balance terhadap turnover intention yang dimediasi kepuasan kerja Account officer Bank Syariah di Kota Medan, H7: Ada pengaruh tidak langsung antara stress kerja terhadap turnover intention melalui kepuasan kerja Account officer Bank Syariah di Kota Medan. 


\section{Published April 2019 \\ JURNAL ILMIAH MANAJEMEN DAN BISNIS \\ ISSN 1693-7619 (print) | ISSN 2580-4170 (online), http://jurnal.umsu.ac.id/index.php/mbisnis}

\section{METODE}

Penelitian ini merupakan penelitian kuantitatif non eksperimental. Penelitian dilakukan di 6 (enam) bank syariah di Kota Medan. Keenam bank syariah tersebut adalah Bank Syariah Mandiri, BRI Syariah, BNI Syariah, Bank Muamalat, Bank Bukopin Syariah, Bank Mega Syariah. Data pada penelitian ini dikumpulkan menggunakan kuesioner dengan menggunakan skala likert yang diberikan kepada Account officer di keenam bank syariah tersebut. Jumlah sampel yang digunakan dalam penelitian ini sebanyak 152 orang yang diambil secara acak dari populasi. Pengolahan data yang dilakukan pada penelitian ini menggunakan Structural Equational Modelling (SEM) dengan aplikasi AMOS, dan Uji validitas dan realibilitas kuisioner pada penelitian ini menggunakan uji CFA (Confirmatory Factor Analysis) dengan menggunakan metode subjek terpakai.

\section{HASIL DAN PEMBAHASAN}

Pengujian data yang dilakukan dengan Teknik Full Structural Equation Modelling (SEM) berdasarkan hipotesis yang dikembangkan adalah sebagai berikut:

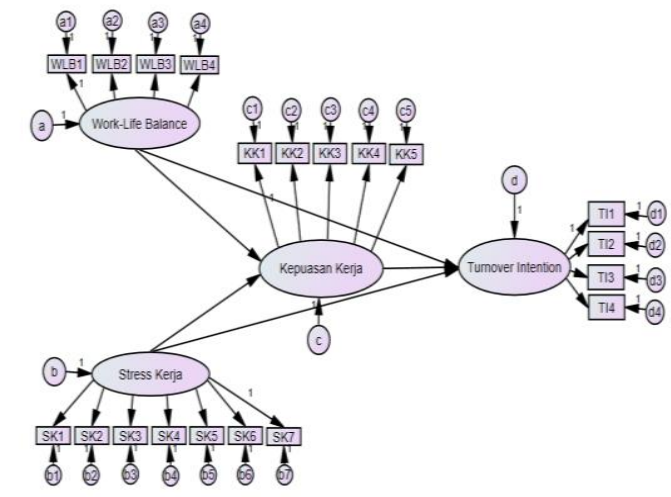

Gambar 2 . Full Model Analisis Structural Equation Modeling (SEM).
Prosedur untuk melakukan estimasi dan penilaian terhadap keselarasan model pada SEM, pada tahap awal melihat estimasi pengukuran keselarasan model (goodness-offit) hasil telaah dapat dilihat pada tabel 1.

Tabel 1. Pengukuran goodness-of-fit

\begin{tabular}{cccc}
\hline $\begin{array}{c}\text { Goodness of Fit } \\
\text { Indeks }\end{array}$ & $\begin{array}{c}\text { Cut off } \\
\text { Value }\end{array}$ & Hasil & $\begin{array}{c}\text { Evaluasi } \\
\text { Model }\end{array}$ \\
\hline CMIN/DF & $<2.00$ & 1,190 & Good Fit \\
\hline Sig. Probability & $>0.050$ & 0,060 & Good Fit \\
\hline GFI & $>0.90$ & 0,829 & Good Fit \\
\hline TLI & $>0.90$ & 0,945 & Good Fit \\
\hline CFI & $>0.90$ & 0,954 & Good Fit \\
\hline RMSEA & $<0.08$ & 0,050 & Good Fit \\
\hline DF & kecil & 42 & Good Fit \\
\hline
\end{tabular}

Berdasarkan hasil evaluasi kelayakan model, keseluruhan indeks telah mencapai angka indeks yang disarankan. Model ini telah memenuhi kriteria goodness of fit, sehingga model ini sudah memenuhi syarat dan dapat digunakan.

Kemudian dilanjutkan dengan pengukuran analisis regression weight yang bertujuan untuk melihat seberapa besar pengaruh antar variabel-variabel yang diuji pada penelitian. Hasil uji analisis regression weight pada penelitian ini adalah sebagai berikut: 
Tabel 2. Tabel hasil pengolahan data

\begin{tabular}{llcrccc}
\hline $\mathrm{H}$ & & Variabel & & Standardized $(\beta)$ & S.E. & C. R \\
\hline $\mathrm{H} 1$ & Work-Life Balance & $\rightarrow$ & Kepuasan Kerja & 0,406 & 0,178 & 3,230 \\
$\mathrm{H} 2$ & Stress Kerja & $\rightarrow$ & Kepuasan Kerja & $-0,866$ & 0,276 & $-3,370$ \\
$\mathrm{H} 3$ & Work-Life Balance & $\rightarrow$ & Turn Over Intention & $-0,653$ & 0,452 & 2.220 \\
$\mathrm{H} 4$ & Stress Kerja & $\rightarrow$ & Turn Over Intention & 0,846 & 0,159 & 6,181 \\
$\mathrm{H} 5$ & Kepuasan Kerja & $\rightarrow$ & Turn Over Intention & $-0,864$ & 0,428 & 4,482 \\
$\mathrm{H} 6$ & Work-Life Balance & $\rightarrow \mathrm{KK} \rightarrow$ & Turn Over Intention & & 0,174 & \\
$\mathrm{H} 7$ & Stress Kerja & $\rightarrow \mathrm{KK} \rightarrow$ & Turn Over Intention & & $-0,052$ & \\
\hline
\end{tabular}

Keseimbangan kerja dan kehidupan pribadi berpengaruh signifikan terhadap kepuasan kerja sebesar $40 \%$ dengan arah hubungan positif. Artinya adalah, bahwa setiap adanya peningkatan keseimbangan kerja dan kehidupan pribadi sebesar $1 \%$ akan memberikan dampak pada peningkatan kepuasan kerja sebesar $40 \%$. Karyawan yang merasa seimbang antara kehidupan pribadi dengan pekerjaannya akan makin merasa puas dengan pekerjannya.

Stres kerja berpengaruh negatif signifikan terhadap kepuasan kerja sebesar $86 \%$. Hal ini menggambarkan bahwa setiap adanya peningkatan stres kerja pada karyawan, akan berpengaruh negatif atau mengurangi kepuasan kerja karyawan sebesar $86 \%$. Kontribusi stres kerja dalam menurunkan kepuasa kerja cukup tinggi. Oleh karenanya, karyawan yang stres akan cenderung merasa tidak puas dengan pekerjaannya

Keseimbangan kerja dan kehidupan pribadi berpengaruh signifikan terhadap niat karyawan untuk mengundurkan diri dengan arah hubungan negatif sebesar 65\%. Hasil ini menunjukkan bahwa karyawan yang merasa seimbang antara pekerjaan dan kehidupan pribadi cenderung akan bertahan pada pekerjaannya.

Pada penelitian ini, stres kerja memberikan pengaruh positif signifikan terhadap niat karyawan dalam mengundurkan diri sebesar $84 \%$. Hasil pengukuran ini menunjukkan bahwa karyawan yang merasakan stres pada pekerjaannya cenderung akan memiliki niat untuk mengundurkan diri dari pekerjaannya tersebut.

Kepuasan kerja memberikan pengaruh negatif terhadap niat mengundurkan diri sebesar $86 \%$. Hasil pengukuran ini menunjukkan bahwa apabila kepuasan kerja karyawan meningkat maka karyawan cenderung akan bertahan pada pekerjaannya tersebut.

Hasil pengujian efek tidak langsung (indirect effect), terlihat bahwa keseimbangan kerja dan kehidupan pribadi melalui kepuasan kerja memberikan pengaruh sebesar $17 \%$. Pengaruh tidak langsung ini menggambarkan, bahwa keseimbangan kerja dan kehidupan pribadi ditambah dengan kepuasan kerja akan mengurangi niat karyawan dalam mengundurkan diri. Keseimbangan antara pekerjaan dan kehidupan pribadi yang dirasakan karyawan jika ditambah dengan perasaan puas terhadap pekerjannya saat ini akan makin menurunkan keinginannya untuk mengundurkan diri. Kontribusinya kepuasan kerja tidak terlalu besar prosentasenya, karena keseimbangan antara pekerjaan dan kehidupan bisa jadi dipandang sudah cukup meskipun karyawan tidak terlalu puas dengan pekerjaannya tersebut.

Hasil pengujian variabel intervening ini menunjukkan bahwa stes kerja pada karyawan melalui kepuasan kerja akan memberikan pengaruh negatif terhadap niat mengundurkan diri. Hal ini menunjukkan bahwa meskipun kondisi stress dapat meningkatkan niat mengundurkan diri, tetapi ketika kepuasan kerja karyawan masih tinggi karyawan tetap akan bertahan pada 
pekerjaannya saat ini. Di sisi lain, pengukuran menunjukkan bahwa kontribusi kepuasan kerja hanya sebesar 5\%, yang artinya pengaruh yang diberikan tidak terlalu besar, karena karyawan yang stress tetap akan cenderung merasa tidak puas dan kemudian memilih untuk mengundurkan diri.

\section{Pembahasan}

Pengaruh Work life balance terhadap kepuasan kerja. Work life balance dapat memiliki pengaruh yang positif dan negatif terhadap aspek psikologi karyawan, ada dua aspek Work life balance diantaranya dalam kehidupan kerja konflik kehidupan kerja dapat berupa positif atau negatif terhadap aspek psikologis pekerja, ada dua aspek Work life balance diantaranya dapat mengganggu kehidupan keluarga dan keluarga dapat mengganggu pekerjaan (Arunika \& Kottawatta, 2015), dimana hasil penelitian ini membuktikan bahwa stress kerja berpengaruh negatif dan signifikan terhadap kepuasan kerja. Hasil penelitian ini sejalan dengan penelitian Arif \& Farooqi, (2014); Rania, et al., (2011); Malik, et al., (2014); Hafeez \& Akbar, (2015) yang menyatakan bahwa Work life balance memeliki pengaruh positif terhadap kepuasan kerja, keseimbangan pekerjaan harus dimiliki oleh setiap karyawan agar mereka merasakan kepuasan dalam menjalani pekerjaan.

Meningkatnya stres kerja disertai dengan kinerja yang menurun dan kepuasan kerja, yang akhirnya mengarah pada produktivitas yang lebih rendah dan dapat peningkatan biaya yang dikeluarkan oleh perusahaan (Hoboubi, et al., 2017). Hasil penelitian ini membtuktikan bahwa tress kerja berpengaruh negatif dan signifikan terhadap kepuasan kerja, hasil ini didukung oleh penelitian Nasution, (2017); (Essiam, et al., (2015); Riaz et al., (2016); (Trivellas, et al., (2013) yang mengatakan bahwa stres kerja berpengaruh negatif terhadap kepuasan kerja. Stress kerja tidak berpengaruh positif terhadap kepuasan kerja hal ini dikarenakan bahwa seorang Acount Officer harus bekerja dibawah tekanan dan beban kerja sehingga perusahaan harus mengalami perubahanperubahan yang akan diikuti oleh seluruh karyawan sehingga tidak akan berdampak kepada kepuasan kerja karyawan, seperti apa yang dikatakan bahwa stres kerja tidak ada hubungan dengan kepuasan kerja (Agarwal, 2015).

Work life balance menjadi masalah yang penting bagi perusahaan secara umum, Work life balance erat dengan turnover intention (Noor, 2011), penelitian berhasil menemukan temuan bahwa Work life balance berpengaruh positif dan signifikan terhadap turnover intention. Suifan, et al., (2016) menyebutkan Work life balance akan memiliki efek pada keinginan untuk keluar dari perusahaan jika tidak mendapakan dukungan dari atasan, serta tidak adanya otonomi kerja yang diberikan oleh perusahaan kepada karyawan, beberapa temuan penelitian ini juga sama halnya dengan penelitian Fayyazi \& Aslani, (2015); Khan et al., (2014); Atiq, et al., (2017) yang mengatakan bahwa Work life balance berpengaruh positif dan signifikan terhadap turnover intention, work life balace sangat penting dilkukan oleh perusahaan untuk mengurangi turnover intention.

Turnover karyawan juga terjadi pada perusahaan Bank Syariah di Kota Medan, diantarnya dikarekanan Account officer mengalami stres yang diakibatkan oleh pekerjaan, terbukti penelitian ini menemukan bahwa Stres kerja berpengaruh positif dan signifikan terhadap turnover intention. Beberapa temuan penelitian lainnya juga mengungkapkan bahwa stres kerja berpengaruh terhadap turnover intention, seperti pada penelitian Ulil et al., (2017) ; Nasution, et al., (2017); Hidayati \& Trisnawati, (2016). Perusahaan harus mampu menciptakan lingkungan kerja yang positif, sehigg stres kerja dapat diminimalkan dan 
akan mengurangi turnover intention, disamping itu juga pimpinan harus memiliki kemampuan untuk mendorong tim kerja agar para karyawan tidak mengalami stress yang berlebihan, (Saraswati \& Subudi, 2017) juga menguatkan temuan ini bahwa hak dan kewajiban karyawan harus selalu diterima dan dijalankan dengan baik, sehingga turnover intention dapat diurungkan oleh seluruh Account officer.

Jika Account officer merasakan kepuasan dalam melaksanakan pekerjaan, maka turnover intention tidak akan dimiliki oleh karyawan, hal ini sesuai dengan temuan penelitian ini bahwa Kepuasan kerja berpengaruh negatif dan signifikan terhadap turnover intention. Karyawan yang memiliki tingkat kepuasan tinggi akan memperlihatkan sikap kerja yang positif (Alamsyah \& Kusumadewi, 2016), sejalan dengan hasil penelitian Hidayat, (2018).

Work life balance berpengaruh secara langsung terhadap turnover intention tanpa melalui kepuasan kerja, atau dengan kata lain kepuasan kerja bukan variabel intervening sedagnkan stress kerja berpengaruh secara langsung terhadap turnover intention tanpa melalui kepuasan kerja. Atau dengan kata lain kepuasan kerja bukan variabel intervening, artinya Kepuasan (X3) tidak memiliki peran penting dalam model penelitian ini, yakni Kepuasan kerja (X3) bukan menjadi perantara perantara stress kerja terhadap turover intention.

Agar dapat memahami antara kepuasan kerja Work life balance dan kepuasan kerja sehingga memberikan dasar pada penelitian yang akan datang dan sangat bermanfaat untuk kepentingan perusahaan dan individu. Meskipun lingkungan kerja Account officer memiliki beban kerja yang berlebihan, stres kerja bukan berati Turnover intention tidak dapat dihindarkan, hal ini lah yang mengharuskan perusahaan memperkuat kepuasan kerja dan Work life balance
Account officer Bank Syariah di Kota Medan harus mendapatkan perhatian khusus dari Pimpinan perusahaan, agar turnover intention dapat diminimalkan.

\section{SIMPULAN}

Temuan-temuan penelitian telah dikemukakan di atas, berdasarkan hasil penelitin tersebut bahwa Work life balance berpengaruh positif dan signifikan terhadap kepuasan kerja Stres kerja berpengaruh negatif dan signifikan terhadap kepuasan kerja, Work life balance berpengaruh positif dan signifikan terhadap turnover intention, Stres kerja berpengaruh positif dan signifikan terhadap turnover intention, Kepuasan kerja berpengaruh negatif dan signifikan terhadap turnover intention, Work life balance berpengaruh secara langsung terhadap turnover intention tanpa melalui kepuasan kerja, atau dengan kata lain kepuasan kerja bukan variabel intervening, artinya Kepuasan kerja (X3) tidak memiliki peran penting dalam model penelitian ini, Kepuasan kerja (X3) tidak dapat memdiasi antara Work life balance terhadap turnover intention, Stres kerja berpengaruh secara langsung terhadap turnover intention tanpa melalui kepuasan kerja. Atau dengan kata lain kepuasan kerja bukan variabel intervening, artinya Kepuasan (X3) tidak memiliki peran penting dalam model penelitian ini, yakni Kepuasan kerja (X3) bukan menjadi perantara perantara stress kerja terhadap turover intention, Besar pengaruh variabel Work life balance, stress kerja dan kepuasan kerja terhadap turnover intention pegawai marketing Bank Syariah di Kota Medan yang dapat dijelaskan oleh model penelitian ini adalah sebesar $87,6 \%$ sedangkan sisanya dipengaruhi oleh faktorfaktor lain yang tidak dimasukkan dalam model penelitian ini. Pembahasan Sumber Daya Manusia sangat luas, hal ini yang menyebabkan penulis hanya menguji Work life balance, stres kerja dan kepusan kerja, 
turnover intention yang menjadi variabel penelitian, Kajian ini akan terus dilanjutkan sampai menemukan ilmu-ilmu baru dalam meningkatkan pengelolaan sumber daya manusia di Bank Syariah. Sangat Banyaknya Account officer di Kota Medan, maka peneliti juga hanya mengambil sampel pada Bank Syariah di Kota Medan, sehingga pada masa yang akan datang dapat dilakukan penelitian pada Bank konvensional

\section{REFERENSI}

Abdurrahim, \& Anisah, H. U. (2015). Pengaruh Kepuasan Kerja Dan Komitmen Organisasi Terhadap Turnover Intention Karyawan (Studi pada PT. Bank Perkreditan Rakyat Mitratama Arthabuana). Jurnal Wawasan Manajemen, 3(3), 191-202.

Agarwal, R. N. (2015). Stress, Job Satisfaction And Job Commitment'S Relation With Attrition With Special Reference To Indian It Sector. In Proceedings of the 9TH International Management Conference "Management and Innovation For Competitive Advantage”, November 5th-6th, 2015 (pp. 720-731). Bucharest, Romania.

Alamsyah, P. A., \& Kusumadewi, I. (2016). Pengaruh Stres Kerja, Kepuasan Kerja , Dan Kepuasan Atas Gaji Terhadap Turnover Intention Karyawan ( PT. Adira Semesta Idustry Cabang II Sumedang). Jurnal J-Ensitec, 03(01), 14-20.

Arif, B., \& Farooqi, Y. A. (2014). Impact of Work life balance on Job Satisfaction and Organizational Commitment Among University Teachers: A Case Study of University of Gujrat, Pakistan. International Journal Of Multidisciplinary Sciences and Engineering, 5(9), 24-29.

Arunika, M., \& Kottawatta, H. (2015). The Effect of Work life balance on Employee Job Satisfaction among Non
Executives in the Public Banking Sector in Colombo District. Human Resource Management Journal, 03(01), 60-71. https://doi.org/10.31357/hrmj.v3i1.2936 Asepta, U. Y., \& Maruno, S. H. P. (2007). Analisis Pengaruh Work-Life Balance Dan Pengembangan Karir Terhadap Kepuasan Kerja Karyawan PT. Telkomsel, Tbk Branch Malang. Jurnal JIBEKA, 11(1), 77-85.

Astianto, A., \& Suprihhadi, H. (2014). Pengaruh Stres Kerja dan Beban Kerja Terhadap Kinerja Karyawan PDAM Surabaya. Jurnal Ilmu \& Riset Manajemen, 3(7), 1-17.

Atiq, M. S., Iqbal, S., \& Rasheed, M. (2017). Work life balance And Intention To Quit Among Female Work Force. In 3rd Asia Pacific Conference on Contemporary Research (APCCR2017) (pp. 31-40). Kuala Lumpur, Malaysia.

Bintang, S. K., \& Astiti, D. P. (2016). WorkLife Balance Dan Intensi Turnover Pada Pekerja Wanita Bali Di Desa Adat Sading, Mangupura, Badung. Jurnal Psikologi Udayana, 3(3), 382-394.

Dewi, C. N. C., Bagia, I. W., \& Susila, G. P. A. J. (2014). Pengaruh Stres Kerja Dan Kepuasan Kerja Terhadap Kinerja Karyawan Pada Bagian Tenaga Penjualan Ud Surya Raditya Negara. EJournal Bisma, 2(2), 1-9.

Dewi, K. A. B. P., \& Wibawa, I. M. A. (2016). Pengaruh Stres Kerja Pada Turnover Intention Yang Dimediasi Kepuasan Kerja Agen Ajb Bumiputera 1912. E-Jurnal Manajemen Universitas Udayana, 5(6), 3560-3588.

Dini, E. S., \& Sari, M. K. (2013). Pengaruh Latar Belakang Pendidikan Dan Pelatihan Terhadap Kinerja Account officer (Ao) Kredit Komersial Bank Bri Sumatera Barat. Jurnal Administrasi Bisnis, 6(2), 1-8.

Essiam, J. O., Mensah, M. E., Kudu, L. K., \& 
Gyamfi, G. D. (2015). Influence Of Job Stress On Job Satisfaction Among University Staff: Analytical Evidence From A Public University In Ghana. International Journal of Economics, Commerce and Management, 3(2), 115.

Fayyazi, M., \& Aslani, F. (2015). The impact of work-life balance on employees' job satisfaction and turnover intention; the moderating role of continuance commitme. International Letters of Social and Humanistic Sciences, 51(im), 33-41. https://doi.org/10.18052/www.scipress. com/ILSHS.51.33

Hafeez, U., \& Akbar, W. (2015). Impact of work-life balance on job satisfaction among school teachers of the 21st century. Australian Journal of Business and Management Research, 4(11), 2237.

Handoko, T. (2011). Manajemen Personalia dan Sumberdaya Manusia (Edisi Kedu). Yogyakarta: Penerbit BPFE.

Harnoto. (2002). Manajemen Sumber Daya Manusia (Edisi 2). Jakarta: PT. Prehallindo.

Hidayat, A. S. (2018). Pengaruh Kepuasan Kerja Terhadap Komitmen Organisasi Dan Turnover Intention. Jurnal Manajemen Dan Pemasaran Jasa, 11(1), 51-56.

Hidayati, N., \& Trisnawati, D. (2016). Pengaruh Kepuasan Kerja Dan Stres Kerja Terhadap Turnover Intentions Karyawan Bag Marketing PT Wahana Sahabat Utama. Jurnal Eksis, 11(1), 22-37.

Hoboubi, N., Choobineh, A., Kamari Ghanavati, F., Keshavarzi, S., \& Akbar Hosseini, A. (2017). The Impact of Job Stress and Job Satisfaction on Workforce Productivity in an Iranian Petrochemical Industry. Journal Safety and Health at Work, 8(1), 67-71. https://doi.org/10.1016/j.shaw.2016.07. 002

Hutcheson, P. (2012). Work-Life Balance (Book 1). USA: IEEE-USA.

Khan, M. R., Nazir, N., Kazmi, S., Khalid, A., Kiyani, T. M., \& Shahzad, A. (2014). Work-Family Conflict and Turnover Intentions: Mediating Effect of Stress. International Journal of Humanities and Social Science, 4(5), 92-100.

Luthans, F. (2006). Perilaku Organisasi (Edisi Sepu). Yogyakarta: Andi.

Malik, M., Wan, D., Dar, L., Akbar, A., \& Naseem, M. A. (2014). The Role Of Work life balance In Job Satisfaction And Job Benefit. The Journal of Applied Business Research, 30(6), 1627-1638.

Manurung, M. T., \& Ratnawati, I. (2012). Analisis Pengaruh Stres Kerja dan Kepuasan Kerja terhadap Turnover Intention Karyawan (Studi pada STIKES Widya Husada Semarang). Diponegoro Journal Of Management, 1(2), 145-157.

Maslichah, N. I., \& Hidayat, K. (2017). Pengaruh Work-Life Balance Dan Lingkungan Kerja Terhadap Kepuasan Kerja Karyawan (Studi Pada Perawat Rs Lavalette Malang Tahun 2016). Jurnal Administrasi Bisnis (JAB), 49(1), 60-68.

McDonald, P., \& Bradley, L. M. (2005). The Case for Work/Life Balance: Closing the Gap Between Policy and Practice.

Nafiudin. (2015). Pengaruh Work life balance Dan Kepuasan Kerja Terhadap Turnover Intention Karyawan Pada Pt Bank Agroniaga Tbk Cabang Bandung. Jurnal Sains, 1(1), 24-38.

Nafiudin, \& Umdiana, N. (2017). Analisis Faktor-Faktor Yang Mempengaruhi Turnover Intention Karyawan Generasi 
Y Di Provinsi Banten. Jurnal Sains Manajemen, 3(2), 69-91.

Nasution, M. I. (2017). Pengaruh Stress Kerja, Kepuasan Kerja dan Komitmen Organisasi terhadap Turnover Intention Medical Representative. MIX: Urnal Ilmiah Manajemen, 7(3), 407-428.

Nasution, W. A. (2009). Pengaruh Kepuasan Kerja Karyawan Terhadap Intensi Turnover Pada Call Center Telkomsel Di Medan. Jurnal Mandiri, 4(1), 2-11.

Nazenin, S., \& Palupiningdyah. (2014). Peran Stres Kerja Dan Kepuasan Kerja Untuk Mengurangi Turnover Intention. Jurnal Dinamika Manajemen, 5(2), 220-227.

Nisa, H. D. W., Suharsono, Y., \& Ingarianti, T. M. (2012). Hubungan Antara Iklim Organisasi Dengan Intensi Turnover Pada Karyawan. In Prosiding Seminar Nasional Peran Budaya Organisasi Terhadap Efektivitas dan Efisiensi Organisasi (pp. 74-94).

Noor, K. M. (2011). Work-Life Balance and Intention to Leave among Academics in Malaysian Public Higher Education Institutions. International Journal of Business and Social Science, 2(11), 240-248.

Nurendra, A. M., \& Saraswati, M. P. (2016). Model Peranan Work life balance, Stres Kerja Dan Kepuasan Kerja Pada Karyawan. Jurnal Humanitas, 13(2), 84-94.

Oosthuizen, R. M., Coetzee, M., \& Munro, Z. (2016). Work-life balance, job satisfaction and turnover intention amongst information technology employees. Southern African Business Review, 20, 446-467.

Pahi, M. H., Hamid, K. A., \& Khalid, N. (2016). Save Talent of Banking Sector of Pakistan: Mediating Job Satisfaction between Job Stress and Employee Turnover Intention. International Review of Management and Marketing, 6(3), 617-624.
Prawitasari, A. (2016). Faktor-Faktor Yang Mempengaruhi Turnover Intention Karyawan Pada Pt . Mandiri Tunas Finance Bengkulu. Ekombis Review, 4(2), 177-186.

Rania, S., Kamalanabhan, \& Selvarania. (2011). FullWork / Life Balance Reflections On Employee Satisfaction. Serbian Journal of Management, 6(1), 85-96.

Riaz, M., Ahmad, N., Riaz, M., Murtaza, G., Khan, T., \& Firdous, H. (2016). Impact of Job Stress on Employee Job Satisfaction. International Review of Management and Business Research, 5(4), 1370-1382.

Risna, Sakka, A., \& Yunawati, I. (2017). Pengaruhwork-Life Balance (Keseimbangan Kehidupan Kerja) Terhadap Kepuasan Kerja Perawat Pada Tenaga Kerja Perawat Di Badan Layanan Umum Daerah (Blud) Rumah Sakit Konawe Selatan Tahun 2016. Jurnal Jimkesmas, 2(5), 1-11.

Robbins, S. (2012). Perilaku Organisai. Jakarta: Salemba Empat.

Robbins, S. P., \& Judge, T. A. (2008). Perilaku Organisasi (Organizational Behavior) (Edisi Kedu). Jakarta: Penerbit Salemba Empat.

Saraswati, V. P., \& Subudi, M. (2017). Pengaruh Konflik Pekerjaan-Keluarga Dan Stres Kerja Terhadap Turnover Intention. E-Jurnal Manajemen Unud, 6(6), 2995-3021.

Sudita, I. N. (2015). Pengaruh Kepuasan Gaji, Kepuasan Kerja, Dan Komitmen Organisasional Terhadap Turnover Intention. Efektif Jurnal Bisnis Dan Ekonomi, 6(1), 89-99.

Suifan, T. S., Abdallah, A. B., \& Diab, H. (2016). The Influence of Work life balance on Turnover Intention in Private Hospitals : The Mediating Role of Work Life Conflict. European Journal of Business and Management, 
$8(20), 126-139$.

Syakir, A. (2014). Peran Account officer dan perkembangan pembiayaan pada perbankan syariah. Jurnal MADANIA, 18(1), 87-97.

Trivellas, P., Reklitis, P., \& Platis, C. (2013). The Effect of Job Related Stress on Employees' Satisfaction: A Survey in Health Care. In Procedia - Social and Behavioral Sciences (Vol. 73, pp. 718726). Elsevier B.V. https://doi.org/10.1016/j.sbspro.2013.02 .110

Ulil Amri, A. M., \& Riyanto, S. (2017). Pengaruh Kepuasan Kerja, Stres Kerja, Dan Komitmen Organisasi Terhadap Turnover Intention Pada Head Office PT. Thamrin Brothers Palembang. Jurnal Kompetitif, 6(1), 109-128.

Wibowo, I. G. P., Riana, G., \& Putra, M. S. (2015). Pengaruh Stres Kerja Terhadap Kepuasan Kerja Dan Komitmen Organisasional Karyawan. E-Jurnal Ekonomi Dan Bisnis Universitas Udayana, 19(2), 314-325. 